\title{
Why Knowledge Management Systems Fail? \\ Enablers and Constraints of Knowledge Management in Human Enterprises
}

Yogesh Malhotra, Ph.D.

Founding Chairman and Chief Knowledge Architect

BRINT Institute, L.L.C., Syracuse, NY, USA

yogesh.malhotra@brint.com

http://www.yogeshmalhotra.com/

Forthcoming in: Handbook on Knowledge Management (edited by C.W. Holsapple), SpringerVerlag, Heidelberg, 2002

in the "International Handbook on Information Systems" Series. 


\section{Why Knowledge Management Systems Fail? Enablers and Constraints of Knowledge Management in Human Enterprises}

Yogesh Malhotra, Ph.D.

Founding Chairman and Chief Knowledge Architect

BRINT Institute, L.L.C., Syracuse, NY, USA

yogesh.malhotra@brint.com

http://www.yogeshmalhotra.com/

Drawing upon les sons learned from the biggest failure of knowledge management in recent world history and the debacle of the 'new economy' enterprises, this chapter explains why knowledge management systems (KMS) fail and how risk of such failures may be minimized. The key thesis is that enablers of KMS designed for the 'knowledge factory' engineering paradigm often unravel and become constraints in adapting and evolving such systems for business environments characterized by high uncertainty and radical discontinuous change. Design of KMS should ensure that adaptation and innovation of business performance outcomes occurs in alignment with changing dynamics of the business environment. Simultaneously, conceiving multiple future trajectories of the information technology and human inputs embedded in the KMS can diminish the risk of rapid obsolescence of such systems. Envisioning business models not only in terms of knowledge harvesting processes for seeking optimization and efficiencies, but in combination with ongoing knowledge creation processes would ensure that organizations not only succeed in doing the thing right in the short term but also in doing the right thing in the long term. Embedding both these aspects in enterprise business models as simultaneous and parallel sets of knowledge processes instead of treating them in isolation would facilitate ongoing innovation of business value propositions and customer value propositions.

Keywords: Design of Successful Knowledge Management Systems; Enablers and Constraints of Knowledge Management; Adaptive Systems for Radical Discontinuous Change; Knowledge Harvesting and Knowledge Creation; Information Processing and Sense Making; Strategic, Social, and, Behavioral Aspects of Knowledge Management; Transformation of Knowledge Work and Knowledge Organizations; Business Value Propositions and Customer Value Propositions; Knowledge Management Failure; Business Model Innovation; New Business Models

\section{Introduction}

The advent of the era characterized by high uncertainty was announced by a recent Business Week (2001) cover story that determined September 11, 2001, as the day of the watershed event. On this day, the unprecedented combination of conventional means of terrorism inflicted their wrath on thousands of human lives in the World Trade Center twin towers despite policy-makers' preoccupation with unconventional means of terror. The basic premises guiding the knowledge processes of the intelligence machinery and policy-makers' decision models surmised that:

- unconventional means pose greater risk compared with those posed by conventional means;

- conventional means cannot reconfigure in unpredictable ways to pose greater risk than unconventional means;

- impact of human and technology inputs can be determined with a safe margin of predictability;

- hi-tech inputs always have greater impact than low-tech inputs;

- human inputs play a lesser role compared with technology inputs and financial capital inputs in the input-outcome equation; and,

- inputs rather than the execution strategy primarily determine the outcomes.

In retrospective it was found that all these assumptions were questionable. A review of the above assumptions guiding policy making decisions offers some interesting revelations listed below: 
- Pre-specified and pre-determined notions of unconventional and conventional, and, low-tech and high-tech inputs may not necessarily be always applicable;

- Technology inputs and financial capital inputs may be less relevant factors in the input-outcome equation given unconventional strategy of execution that defines how creatively and innovatively inputs are deployed to produce unprecedented outcomes;

- Human inputs may not necessarily play a lesser role than technology inputs or financial capital inputs in the input-outcome equation - given highly committed and motivated humans and their leaders, technology inputs and financial capital may assume a lesser role in the inputoutcome equation.

Extending the same analysis to understand the recent debacle of 'new economy' enterpris es also offers some interesting insights. Given the euphoria about the Internet technologies and the pitch of the venture capitalists and tech stock analysts and underwriters, Internet technology based businesses were summarily branded as unconventional in contrast to the conventional enterprises of the brick-and-mortar economy. It was assumed that conventional enterprises must get up on the Internet bandwagon if they had to survive in the future. It was assumed that given enough investment of venture capital, technology, and hype, any company could create and sustain successful business performance outcomes within a very short time. In summary, the following premises guided the euphoria about the Internet based companies which was compounded by the over-exuberance of media network reporters and the analysts:

- unconventional means pose greater risk compared with those posed by conventional means;

- conventional means cannot reconfigure in unpredictable ways to pose greater risk than unconventional means;

- impact of human and technology inputs can be determined with a safe margin of predictability;

- hi-tech inputs always have greater impact than low-tech inputs;

- human inputs play a lesser role compared with technology inputs and financial capital inputs in the input-outcome equation; and,

- inputs rather than the execution strategy primarily determine the outcomes.

Given the recent spate of Internet-based company failures, reversal of faith in the Net-based companies has been pervasive. This has happened despite the fact that widespread weaknesses are being observed in many sectors of the economy including many industries and companies that represent the tried-and-tested 'old economy'. It is time to reflect upon the lessons learned from the biggest failures of knowledge management in recent world history and the debacle of the 'new economy' enterprises. This is important to inform the prevailing myth about the intrinsic infallibility of 'old economy' enterprises in contrast with the 'new economy' enterprises despite dependence of both on the same fundamentals.

Based upon the earlier analysis, one can offer the following hypotheses that seem to offer a more robust basis for defining, implementing, and executing effective knowledge management systems.

- The impact of human and technology inputs cannot be determined with safe margin of predictability as the business performance outcomes are separated from these inputs by intervening variables. Such variables include effective acceptance and utilization of technologies by humans; motivation and commitment for adoption of these technologies and for achieving the specified performance outcomes; and, contextual interpretation of information resulting in diverse subjective decisions and actions. Pre-specified outcomes may also become marginalized with the changing business environment when the inputs are consumed for doing the thing right even though it may not be the right thing any more.

- Lo-tech and hi-tech inputs are constrained or enabled by knowledge workers who utilize these inputs as well as by the strategy of execution that may together produce different outcomes despite similar mix of the inputs. The contrast between lo-tech and hi-tech is based upon context-specific 
perspectives and as business contexts change, these contrasts may change or become immaterial with emergence of newer and unprecedented inputs.

- The contrast between unconventional and conventional means of producing business performance outcomes is based upon context-specific perspectives. As business contexts change such contrast may become marginalized with emergence of newer and unprecedented means as well as unprecedented outcomes. Such contrast may also become marginalized if conventional means are configured in unprecedented ways to achieve unprecedented outcomes. In this discussion, it is observed that unprecedented business performance outcomes are realized as a result of new business value propositions and customer value propositions.

This article explains how both old and new economy enterprises having any mix of brick-and-click strategies are vulnerable to the above failures. Such failures result from the gaps between the input resources and the business performance outcomes, and, the gaps between the value these enterprises create and the value demanded by changing market conditions, consumer preferences, competitive offerings, and, changing business models, and, industry structures. KMS are often defined in terms of inputs such as data, information technology, best practices, etc., which by themselves may inadequately explain business performance outcomes. Often, moderating and intervening variables may play a significant role in skewing the simplistic relationships based upon correlation of the above inputs with business performance outcomes. Also, usefulness of such inputs and how they are strategically deployed are important issues often left unquestioned as 'expected' performance outcomes are achieved, but the value of such performance outcomes gets eroded by the dynamic shifts in the business and competitive environments. The remaining discussion will explain why KMS fail; how enablers of KMS designed for the 'knowledge factory' engineering paradigm become constraints in adapting and evolving such systems for business environments characterized by high uncertainty and radical discontinuous change; and, how risk of such failures may be minimized.

\section{Knowledge Management for Routine and Structured Information Processing (Model 1 KMS)}

Given the centrality of computerized information processing in most mainstream conceptualizations of knowledge management, most KMS primarily depend upon routines that are programmed in the logic of computational machinery and on data residing in data warehouses. [A detailed discussion about such definitions of knowledge management is available elsewhere (Malhotra 2000a, 2000b). A recent historical perspective of knowledge management is available in Prusak (2001).] Based on the pre-specification and pre-determination of the programmed logic connecting 'information inputs' and consequent 'information outcomes', such systems are based upon consensus, convergence, and, compliance to ensure adherence to organizational routines. The mechanistic model of information processing and control based upon compliance is not only limited to the computational machinery, but extends to specification of goals and tasks and the best practices and institutionalized procedures to achieve those pre-specified outcomes. Motivated by emphasis on optimization and efficiencies of scale, the above logic of knowledge management has evolved from 'scientific' Taylorism and the assembly line techniques applied by Henry Ford in the production of Model T.

Not surprisingly, the original versions of such KMS were reified in the interpretations of some Information Systems researchers who seemed to believe that technology inputs, rather than knowledge workers, would play a predominant role in the performance outcome equation discussed earlier. One example of such systems was offered in a popular Information Systems textbook published by professors at the Harvard Business School (Applegate et al., 1988, p. 44):

"Information systems will maintain the corporate history, experience and expertise that long-term employees now hold. The information systems themselves -- not the people -- can become the stable 
structure of the organization. People will be free to come and go, but the value of their experience will be incorporated in the systems that help them and their successors run the business."

Not surprisingly, many business and technology executives trained in similar reasoning have been trying to push for adoption of computer technologies for storing their employees' knowledge in computerized databases and programmed logic of the computing machinery with mixed results. Best practices, benchmarks, and rules tend to define the assumptions that are embedded not only in information databases, but also in the organization's strategy, reward systems, and resource allocation systems.

A recent interpretation of the same reasoning, illustrated in Figure 1, based upon pre-definition, prespecification, and, pre-determination is offered in a definition popularized by the Gartner Group (cf: Oracle Magazine, 1998):

"Knowledge Management promotes an integrated approach to identifying, capturing, retrieving, sharing, and evaluating an enterprises information assets. These information assets may include databases, documents, policies, procedures, as well as the un-captured tacit expertise and experience stored in individual's heads."

Such inputs-oriented mechanistic and static representations of knowledge do not provide any hint as to how these inputs would affect business performance. Nor do they suggest how to deal with "associated emotions and specific contexts" (Nonaka \& Takeuchi 1995, p. 63) that characterize tacit knowledge.

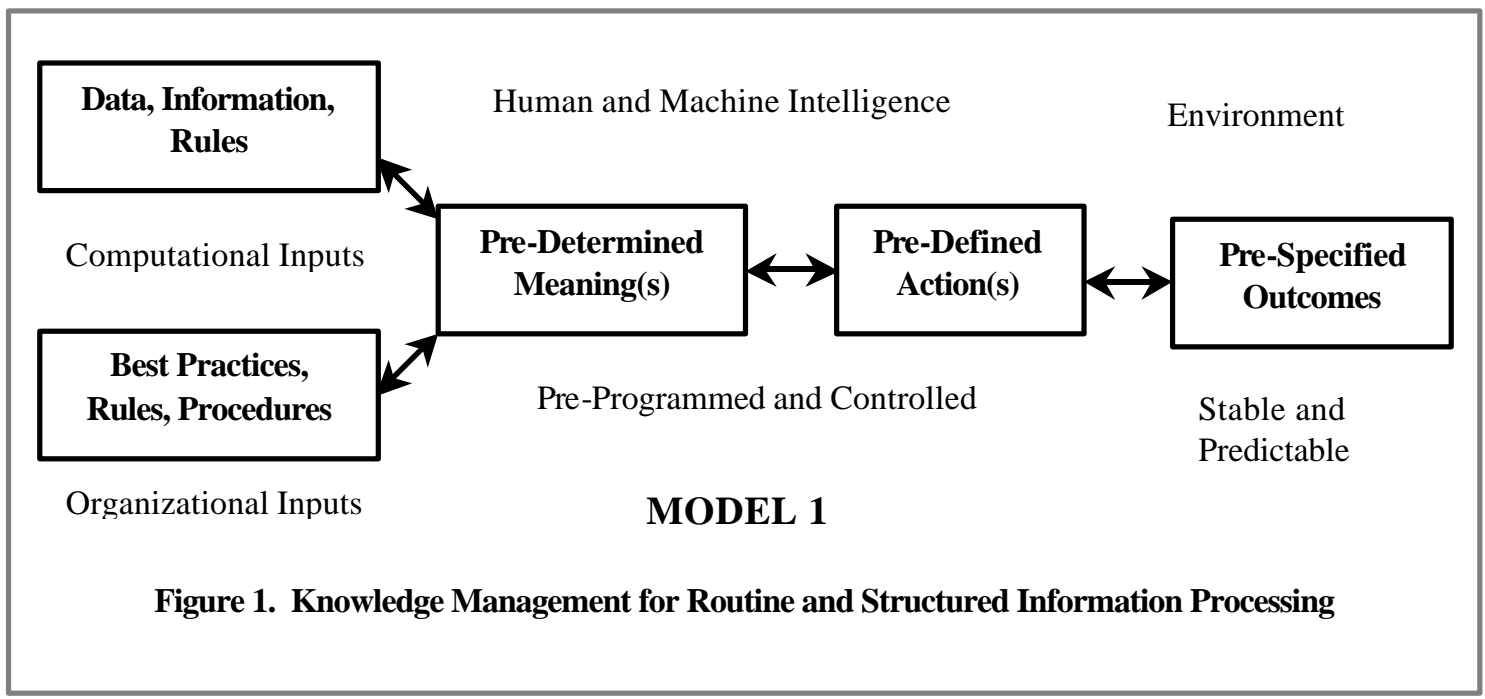

Recent thrust of some organizational knowledge management initiatives on archiving 'best practices' and 'what we know' to guide future decisions and actions is also based on a relatively predictable view of the business environment. Not surprisingly, this model of knowledge management guided by pre-specification and pre-determination of business logic with primary emphasis on optimizing the user of existing knowledge [reified in best practices, computational logic, data warehouses, etc.] has primarily focused on knowledge re-use over creation of new knowledge. This model is based upon managerial focus on seeking consensus and compliance to minimize variance so that pre-specified business performance outcomes are achieved. In this model of knowledge management, conformance to pre-specified and pre-determined business logic is expected to ensure pre-specified and pre-determined business performance outcomes are achieved. 
Not surprisingly, many knowledge management practitioners and researchers who identify with Model 1 discussed above consider information and knowledge as synonymous constructs. In this perspective, both these constructs can be expressed in the computational rule based logic as well as in the form of data inputs and data outputs that trigger pre-defined and pre-determined actions in pre-programmed modes. There is limited, if any, scope for diverse interpretations of the same information by different agents, nor is there any need for multiplicity of meanings based upon the same information. Homogeneity of informationprocessing and control logic is desirable as it ensures that the model works as pre-specified. Inclusion of feedback and feedforward loops may often provide the mechanism for reactive fine-tuning of inputs for optimal conversion of the inputs into outcomes. [Information Systems researchers (cf: Churchman 1971; Mason and Mitroff, 1973; Malhotra, 1997) have dscussed limitations of this model, particularly for environments characterized by uncertainty and radical change.].

Not surprisingly, the goal of KMS based on Model 1 is often characterized as "getting the right information to the right person at the right time." This model is based on the assumption that all relevant knowledge, including tacit knowledge can be stored in computerized databases, software programs, and, institutionalized rules and practices. The distinguishing features of this model are derived from the following assumptions:

(a) the same knowledge can be re-used by any human mind or computer to re-process the same logic to produce the same outcomes;

(b) the same outcomes will be needed and delivered again and again through optimal use of input resources;

(c) the system's primary objective is to achieve the most efficient means for transforming prespecified inputs into pre-determined outcomes; and,

(d) there is no need for subjective interpretation of information - criticism and conflict must be minimized to achieve conformance and compliance.

Model $1 \mathrm{KMS}$ are based on doing the thing right where the pre-specified inputs, processing logic, and, the outcomes are assumed to represent the right thing. The overriding belief is that designers of the systems and the knowledge managers have accurate and complete knowledge about the viability of the input-output transformation process as well as the viability of the performance outcomes that have been pre-defined.

The next section explains the contrasting Model 2 of KMS that is more suited for non-routine and unstructured sense making when deterministic controls encounter uncertain environments characterized by "wide range of potential surprise" that defy predictive logic (Landau and Stout, 1979). Interestingly, many of the limitations of Model 1 may be considered as strengths in Model 2 as the premises of predetermination, pre-definition, and, pre-specification of meanings, actions, and, outcomes become less relevant.

\section{Knowledge Management for Non-Routine and Unstructured Sense Making (Model 2 KMS)}

In Model 2, the construct of knowledge may be better represented as intelligence in action as it is a composite construct resulting from interaction of data, information, rules, procedures, best practices and traits such as attention, motivation, commitment, creativity, and, innovation. This contrasting representation of knowledge as intelligence in action rather than static computerized representations of Model 1 is notable because of several reasons. The active, affective, and dynamic representation of knowledge makes better sense from a pragmatic perspective and is better aligned with theoretical representations of this construct beyond the domain of information technology management. It is active as knowledge is best understood in action - it is not the theory but the practice of theory that makes the difference. It is affective as it takes into consideration not only the cognitive and rational dimensions but also emotional dimensions of human decision-making. It is dynamic as it is based upon ongoing reinterpretation of data, information, and, 
assumptions while pro-actively sensing how decision-making process should adjust to future possibilities. From a pragmatic perspective, the dynamic representation of knowledge provides a more realistic construct where human and social interactions are present while situating this construct more proximal to performance outcomes as illustrated in Figure 2. [A detailed discussion about the active, affective, and dynamic representation of knowledge is available elsewhere (Malhotra 1999, Malhotra and Kirsch (1996), Malhotra (in press)).]

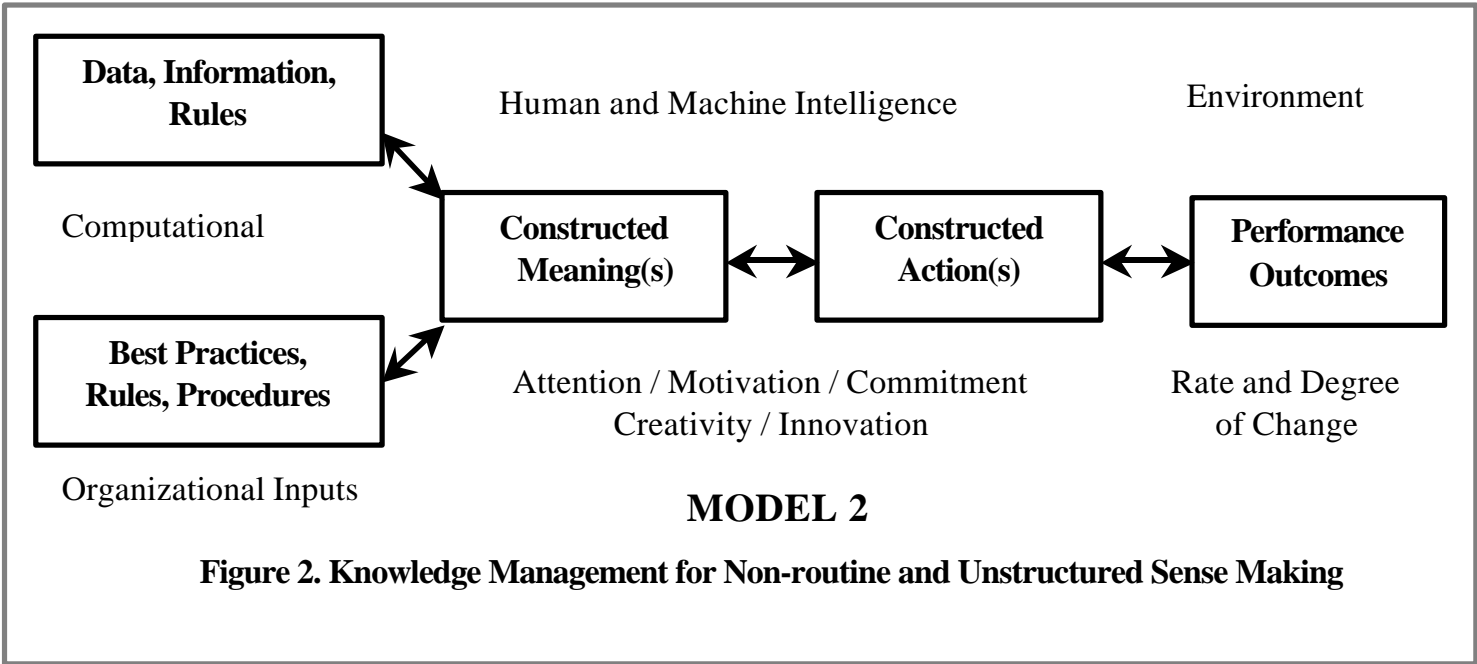

Model 2 provides a better representation of reality as it takes into consideration two key characteristics:

(a) what is done with data, information, and best practices depends upon subjective interpretation ("construction") of individuals and groups that transform these inputs into actions and performance; and,

(b) performance outcomes need to be continuously re-assessed to ensure that they indeed represent best business performance for the enterprise with respect to changing market conditions, consumer preferences, competitive offerings, and, changing business models, and, industry structures.

This view of knowledge management is consistent with some other perspectives that have attempted to address the limitations of Model 1 that is based upon "overdefinition of rules and overspecification of tasks" (Landau and Stout, 1979). For instance, Churchman (1971) has emphasized that: "To conceive of knowledge as a collection of information seems to rob the concept of all of its life... Knowledge resides in the user and not in the collection." Similarly, Nonaka and Takeuchi (1995) had proposed the conceptualization of knowledge as justified belief in their argument that, "knowledge, unlike information, is about beliefs and commitment." On a complementary note, Davenport and Prusak (1998, p. 5) have defined knowledge as deriving from minds at work: "Knowledge is a fluid mix of framed experience, values, contextual information, and expert insight that provides a framework for evaluating and incorporating new experiences and information. It originates in the minds of knowers. In organizations, it often becomes embedded not only in documents or repositories but also in organizational routines, processes, practices, and norms."

As represented in Model 2, knowledge is a dynamic construct in contrast to static representations of Model 1 because diverse [individual and shared] meanings are possible based upon diverse interpretations of the same information inputs across different contexts and at different times. Processing of knowledge through the machinery of information technologies may still be represented by simp lified, highly routine, and, structured forms that permit pre-definition, pre-programming, and, pre-determination of data inputs for 
achieving pre-specified performance outcomes. In contrast, human sense making processes represent a complete contrast, and, human decision-making is influenced by attention, motivation, commitment, creativity, and innovation of individuals and groups. [Related discussion on how "construction of meaning" differs from "the processing of information" is available in Bruner (1990), Kelly (1963), Malhotra (1999), Morris (1938), Strombach (1986). Detailed conceptualization and empirical validation of commitment and motivation constructs as applicable to effective technology use in knowledge work is available in Malhotra (1998), and, Malhotra and Galletta (1999). Contrast between information-processing capabilities of smart technologies and sense-making capabilities of humans is explained in Malhotra (2001a).]

\section{Continuum of KM Systems Between Model 1 and Model 2}

Model 1 works well in predictable and stable environments with primary focus on knowledge harvesting, and, knowledge re-use and replication. Under moderate levels of control, this model could be used for knowledge workers' goal and task specification to achieve pre-specified performance outcomes. This model may be susceptible to failure when creativity and innovation of knowledge workers overwhelms the controls inherent in the pre-specified logic of the input-output transformation process. It is also vulnerable to failure where attention and actions of knowledge workers are significantly influenced by their intrinsic motivation [rather than organizational or institutional rewards and punishments] and commitment to personal goals [rather than organizational or institutional goals]. The ideal scenario is to achieve perfect congruence between extrinsic motivation and intrinsic motivation, and, between organizational goals and individual goals, but this is a formidable challenge for designers of most organizational KMS. [A detailed discussion about the contrast between extrinsic motivation and intrinsic motivation, and, contrast between various levels of commitment is available elsewhere (Malhotra 1998).]

While Model 1 and Model 2 represent the extreme archetypes of KMS, most organizations need some combination of both depending upon their emphasis on knowledge harvesting and knowledge creation. Also, organizations and inter-enterprise value networks contain some business processes that primarily depend upon knowledge harvesting and others that primarily depend upon knowledge creation. This point can be appreciated by considering the two world's of business that often co-exist in many organizations the world of bulk-processing industrial economy and the "world-of-reeverything" of the knowledge economy (Arthur 1996):

"The two worlds are not neatly split. Hewlett-Packard, for example, designs knowledge-based devices in Palo Alto, California, and manufactures them in bulk in places like Corvallis, Oregon or Greeley, Colorado. Most high-tech companies have both knowledge-based operations and bulkprocessing operations. But because the rules of the game are different for each, companies often separate them - as Hewlett-Packard does. Conversely, manufacturing companies have operations such as logistics, branding, marketing, and distribution that belong largely to the knowledge world. And some products - like the IBM PC — start in the increasing returns world, but later in their life cycle become virtual commodities that belong to Marshall's processing world."

Model 1 is relevant to the industrial world of bulk-economy production and Model 2 is relevant to the "world-of-re-everything". Optimization-based routinization of organizational goals and convergence is relevant for 'freezing' the meaning for achieving optimization-based efficiencies. However, 'unfreezing' of meaning embedded in information is critical for reassessing and renewing the routines embedded in business logic and business processes. Business enterprises will need to be facile in both modes despite the apparent contradiction in terms of the business logic and related assumptions. For instance, a key challenge for most organizations with institutionalized 'best practices' is to ensure that such practices remain open to critique, adaptation, and, replacement so that the enterprise is not caught in the death spiral (Nadler and Shaw 1995) of doing more of the same better and better with diminishing marginal returns (Drucker, 1994). Discontinuously changing environments impose upon the organization need for "creative synthesis" resulting from a "dialectical confrontation of opposing interpretations" (Mason and Mitroff 1973, p. 482). Although companies often separate the operations pertaining to the two worlds of business related to Model 
1 and Model 2, both worlds need to be integrated in their business models. For example, given the diminishing margins in the PC markets due to increased competition, computer distributor Dell may need to shift its focus to distribution of servers or to hosting services. To do so effectively, however, it would need to start harvesting [using Model 1] knowledge that it created [using Model 2] earlier through experimentation, adaptation, and innovation related to servers or hosting and it is time to redefine the customer value propositions and the related business value propositions. [How the contrast between the two worlds applies to the use of information technology and knowledge management strategy is discussed in the context of business model innovation in Malhotra (2000d). How the world of 'old economy' and 'new economy' connect with their representation in terms of digitized information and knowledge has been discussed in business literature on virtual organizations, virtual products, and, virtual services, see for instance, Davidow and Malone (1993). More recent research relating knowledge management to virtual organizations and business model innovation is available in Malhotra (2000c) and Malhotra (2001b) respectively.]

As most business environments would include a combination of both stabilizing factors and destabilizing factors, real world KMS implementations should contain combinations of characteristics of both models. The processes of knowledge re-use and knowledge creation need to be balanced by integration of routine and structured information processing and non-routine and unstructured sense making in the same business model. Figure 3 depicts this representation of business model that includes simultaneous and parallel sets of knowledge harvesting and knowledge creation processes.

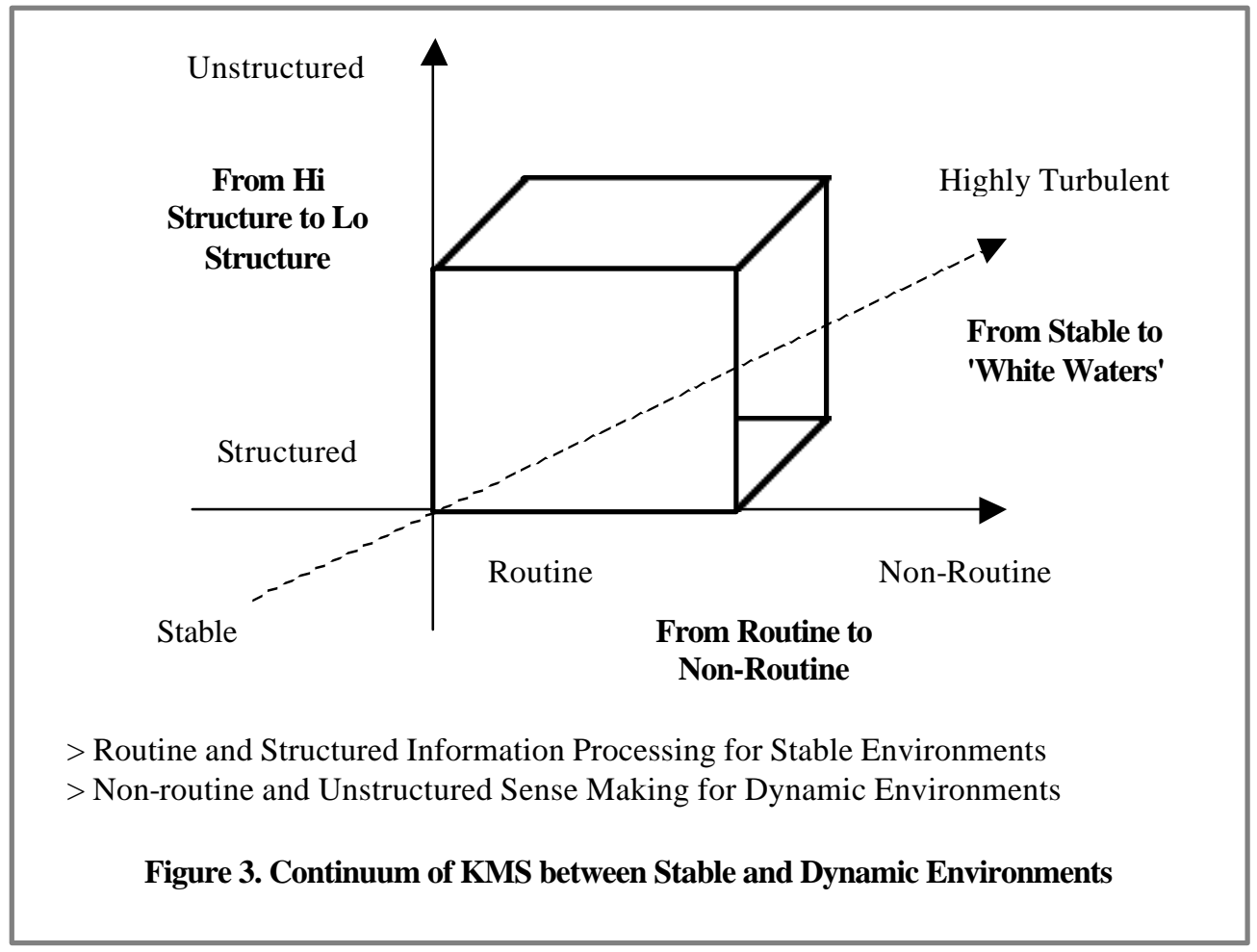

Prior arguments suggest the need for skepticism about the myth of intrinsic infallibility of 'old economy' enterprises in contrast with the 'new economy' enterprises despite dependence of both on the same fundamentals. Both old and new economy enterprises having any mix of conventional and unconventional brick-and-click strategies are vulnerable to the failures resulting from the gaps between their inputs and the business performance outcomes as well as from gaps between the value they create and the value demanded by their customers. Also, despite similarity of inputs and sought market shares, relative success of any business model will be determined more by its execution than by the inputs especially in case of 
rapidly changing environments. As illustrated in Figure 4, new business models for the knowledge economy need to consider Internet and Web simply as elements of the overall business strategy without getting caught in irrational exuberance or despair about these means of producing business value. Just like other inputs and intervening variables, inadequate understanding or application of Internet and Web should not become the basis for outright rejection or degradation of these technologies.

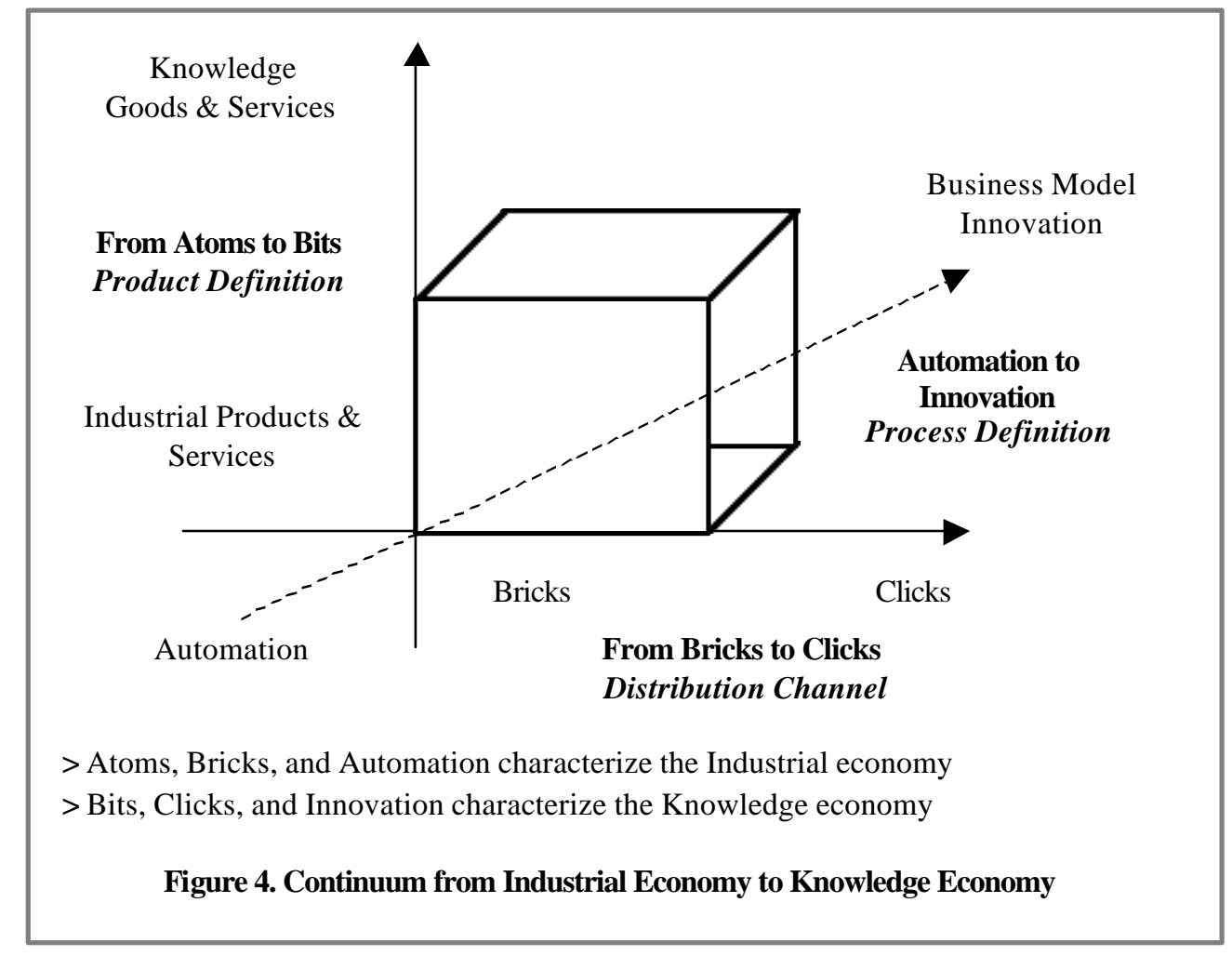

\section{Enablers and Constraints of Knowledge Management Systems}

Prior discussion has highlighted that knowledge management systems fail because of two broad reasons. First, knowledge management systems are often defined in terms of inputs such as data, information technology, best practices, etc., that by themselves may be inadequate for effective business performance. For these inputs to result in business performance, the influence of intervening and moderating variables such as attention, motivation, commitment, creativity, and innovation, has to be better understood and accounted for in design of business models. Second, the efficacy of inputs and how they are strategically deployed are important issues often left unquestioned as 'expected' performance outcomes are achieved, but the value of such performance outcomes may be eroded by the dynamic shifts in the business and competitive environments. These enablers and constraints are presented in the following discussion as seven challenges that need to be met for successful knowledge management. These are called challenges (see Table 1) as they represent both enablers and constraints in different contexts as represented by Model 1 and Model 2. The following discussion highlights how the seven challenges relate to the recent evolution in thinking about business and technology strategy, organizational control, information sharing culture, knowledge representation, organization structure, managerial command and control, and, economic returns. 
Table 1. Enablers and Constraints of KMS: Model 1 and Model 2 Compared

\begin{tabular}{|l|l|l|}
\hline \multicolumn{1}{|c|}{ Enablers \& Constraints } & \multicolumn{1}{c|}{ Model 1 KMS } & \multicolumn{1}{c|}{ Model 2 KMS } \\
\hline Business \& Technology Strategy & Pre-definition of Outcomes & World of re-everything \\
\hline Organizational Control & Control for Consistency & Self-Control for Creativity \\
\hline Information Sharing Culture & Based Upon Contracts & Based Upon Trust \\
\hline Knowledge Representation & Static and Pre-specified & Dynamic and 'Constructed' \\
\hline Organization Structure & Insular and Top-Down & Inclusive and Self-Organized \\
\hline Managerial Command and Control & For Achieving Compliance & For Achieving Commitment \\
\hline Economic Returns & Decreasing Returns & Increasing Returns \\
\hline
\end{tabular}

\subsection{Business and Technology Strategy Challenge of Next Generation KMS}

In the world of re-everything, automation of functions, rationalization of workflows, and redesign of business processes that characterize Model 1 KMS will be inadequate (Malhotra 2000d). Rather, most organizations will need to develop adaptive capacity for redefining their business value propositions - that add greatest value to the business enterprise. Competitive survival and ongoing sustenance would depend on the ability to continuously redefine and adapt organizational goals, purposes, and the organization's "way of doing things." The digital business models will need to accommodate relatively rapid obsolescence of traditional concepts of industries, organizations, products, services and channels of marketing, sales and distribution (Mathur and Kenyon 1997). The critical challenge for most business enterprises will lie in the ability to redesign and reinvent their business processes and business models for realizing more interesting customer value propositions, while harvesting the knowledge flows embedded in the current setup.

Next generation of KMS will need to accommodate the need for ongoing questioning of the programmed logic and very high level of adaptability to incorporate dynamic changes in business models and information architectures. Designers of information architectures will need to ensure that they deliver upon the need for efficiency and optimization for knowledge harvesting while providing for flexibility for facilitating innovative business models and value propositions. Designers will need to provide loose coupling between technology architectures and business architectures so that existing technology infrastructure should not straitjacket the evolution of the business model. Greater technological integration will help in achieving more efficient optimization of for knowledge harvesting. There will be, however, a critical need for ensuring rapid adaptation of the business performance outcomes to the dynamic shifts in the business environment while keeping them loosely coupled with pre-specified technology architectures. The new paradigm of flexible, adaptive, and scalable systems will accommodate real time changes in information and data across the business ecosystems network.

\subsection{Organizational Control Challenge of Next Generation KMS}

Organizational control is imperative in Model 1 KMS to ensure pre-determined meanings, pre-defined actions, and, pre-specified outcomes. Consistency is imperative for ensuring homogeneity of processing of same information in the same manner to ensure same outcomes and is achieved by minimizing criticism and questioning of the status quo. This may, however, take its toll by suppressing innovation and creativity. Even despite organizational control that demands absolute conformance, knowledge workers' attention, motivation, and, commitment may moderate or intervene in its influence. Control is often based on rules and hence difficult to maintain in a world where competitive survival often depends upon questioning existing assumptions. Given an environment characterized by radical and discontinuous change, the survival of the organization would hinge on ongoing assessment of assumptions underlying the business logic as well as ensuring that the definition of business performance outcomes is aligned with the changing market conditions, consumer preferences, competitive offerings, business models, and, industry structures. 
Design of next generation KMS should ensure that they are not constrained by overemphasis on consistency. While the traditional business logic is based on control, dynamics of the new business environment require a business model that assumes existence of few rules, some specific information and a lot of freedom. Within the proposed model, the designers of organizational systems can at best facilitate the organization's 'self-designing'. In this organization design, not only would the knowledge workers define problems and generate their own solutions, the knowledge workers would also evaluate and revise their solution-generating processes. By explicitly encouraging experimentation and rethinking of premises, this model promotes reflection-in-action, creation of new knowledge, and innovation. Organizations will need to be comfortable with the dialectic of harvesting their existing knowledge while being able to rethink and redefine their current models of success before they are marginalized by environmental change.

Integration of data and processes across inter-enterprise value networks will also impose certain challenges of organizational control. On one hand, the players in the inter-enterprise supply chains and extended value chains will need to share information and collaborate with their upstream and downstream partners to ensure streamlined information flows. Ironically, they may also perceive the upstream and downstream players as potential competitors vying for the most attractive and dominant position in the value chain networks. While sharing of accurate information related to goods or services flowing across the supply chain will be necessary, it increases the peril inherent in the paradoxical roles of collaboration and competition adopted by various players in the same supply chain.

\subsection{Information Sharing Culture Challenge of Next Generation KMS}

Success of the next generation KMS will depend upon integration of not only data and processes across inter-enterprise supply chains and value chains, but also integration of decision-making and actions across inter-enterprise boundaries. Effectiveness of integrated information flows will depend upon the accuracy of information that is shared by diverse stakeholders across inter-enterprise boundaries. The challenge of information sharing will result from the potentially competitive nature of various enterprises across the value chains as access to privileged information may often determine the dominant position in the interenterprise value networks. Similarly, access to customer and supplier data residing in databases or networks that are hosted on the infrastructure of outsourcing providers and ASPs may pose increased privacy and security challenges. This is particularly important in situations where sharing of proprietary strategic or competitive information about customer or supplier relationships needs to be safeguarded from third parties. This issue will be particularly relevant if the vendor's knowledge of the company's customers or specific customer relationships may be used against the best interests of the company. There will be need for trusting the vendor(s), however, given the changing business environment, the basis for trust will need to go beyond a simple contractual agreement that would have been sufficient in the deterministic and predictable logic of Model 1.

Often, individuals may not willingly share information with their departmental peers, supervisors or with other departments, because they believe that what they know provides them with an inherent advantage in bargaining and negotiation. Despite the availability of most sophisticated 'knowledge sharing' technologies, such human concerns may often result in sharing of partial, inaccurate, or ambiguous information. Even more critical than the absence of information is the propensity of sharing inaccurate or ambiguous information because of competing interests that may not yield true integration of information flows despite very sophisticated integration of enabling information technologies. Integrated information flows depend upon motivation of people to share accurate information on a timely basis across intraenterprise and inter-enterprise information value chains. Motivation of employees, organizations, customers, and suppliers to share accurate and timely information is based on trust, despite the potential of use of information in unanticipated ways. This in turn depends upon the overriding inter-enterprise and intra-enterprise information sharing cultures. As community and commerce paradigms increasingly intermingle, business enterprises will be challenged to inspire trust and motivation for sharing needed information with their stakeholders on which they may often have little control. Given the lack of these 
enabling factors, it will be almost impossible to ensure that accurate information is available for integration despite presence of enabling technologies that can facilitate such integration.

\subsection{Knowledge Representation Challenge of Next Generation KMS}

Static and pre-defined representation of knowledge is particularly suited for knowledge re-use and offers an interesting contrast against the dynamic, affective, and, active representation of knowledge needed for knowledge creation. The premise of the digitized memory of the past as a reliable predictor of the future success is valid for a business environment characterized by routine and structured change. While the digitized logic and databases can facilitate real-time execution of the inter-enterprise information value chains, their efficacy depends upon real-time adaptation of underlying assumptions to continuously account for complex changes in the business environment. Often such changes cannot be recognized or corrected automatically by computerized systems as they cannot be pre-programmed to detect an unpredictable future. The adaptability of a KMS is therefore dependent upon its capability of sensing complex patterns of change in business environments and using that information for adapting the digitized logic and databases to guide decision-making, actions, and resulting performance outcomes.

AI and expert systems based KMS can deliver the "right information to the right person at the right time" if it is known in advance what the right information is, who the right person to use or apply that information would be, and, what would be the right time when that specific information would be needed. Detection of non-routine and unstructured change in business environment would still depend upon sense-making capabilities of knowledge workers for correcting the computational logic of the business and the data it processes. A related challenge lies in tapping the tacit knowledge of executives and employees for informing the computational logic embedded in the KMS. It may be possible to gather information about the decision-making logic from human experts if such decisions are based on routine and structured information processing. AI and expert systems related technologies enable complex computation of specific and clearly defined domain expertise areas by compiling inferential logic derived from multiple domain experts. The challenge of 'scanning the human mind and its sense making capabilities' lies in the problem that most individuals may know more than they think they know. This is particularly true about their information processing and decision-making capabilities related to non-routine and unstructured phenomena and to knowledge that spans multiple domains. The meaning making capacity of the human mind facilitates dynamic adaptation of tacit knowledge to new and unfamiliar situations that may not fit previously recognized templates. The same assemblage of data may evoke different responses from different people at different times or in different contexts. Hence, storing explicit static representations of individuals' tacit knowledge in technology databases and computer algorithms may not be a valid surrogate for their dynamic sense making capabilities.

\subsection{Organization Structure Challenge of Next Generation KMS}

Developing an information-sharing technological infrastructure is an exercise in engineering design, whereas enabling use of that infrastructure for sharing high quality information and generating new knowledge is an exercise in emergence. While the former process is characterized by pre-determination, pre-specification and pre-programming for knowledge harvesting and exploitation, the latter process is typically characterized by creation of organizational cultural infrastructure to enable continuous information sharing, knowledge renewal, and creation of new knowledge.

Organizational routines embedded in standard operating procedures and policies can become formalized by their implementation in computer programs and databases as the firm's dominant business logic becomes reinforced. Such formalized information systems become inflexible when they are based upon static assumptions about the business environment. With increasingly rapid, dynamic and non-linear changes in the business environment, such systems are increasingly vulnerable because of out-of-date assumptions inherent in their processing logic and the data processed by them. To overcome these vulnerabilities, it is necessary to design technological systems that are sensitive to the dynamic and 
divergent interpretations of information necessary for navigating unforeseen changes in business environment. Subjecting the extant business logic to critique from diverse customer, supplier, and partner perspectives can help in defining innovative customer value propositions and business value propositions by early detection of complex changes in the business environment. Online and offline communities (cf: Malhotra, 2002a; Wenger et al. 2002) of customers, suppliers and partners could provide the means for enabling critical analysis of assumptions underlying given business models.

Expanded role of the customers, suppliers and partners includes their involvement in the creation of 'content', in generating product and service reviews, and in helping each other out on shared concerns. It is important to note that such roles assumed by external communities of customers, suppliers, and partners in the new world have been traditionally delegated to internal customer service representatives and technical support personnel. Hence, in the emerging business models, virtual communities could be rightfully treated as external extensions of the company's service and support infrastructure. Executives must understand the distinction between the lack of structure and lack of controls that characterize self-selected communities and the command and control systems embedded in their formal organizational structures. Such communities may defy compliance seeking tactics as they represent "self-organizing" ecosystems built upon self-control and autonomy. As knowledge work gets transformed and dissipated across the interenterprise value networks, enterprise managers will need to become more comfortable with the model of the enterprise as 'anything, anywhere, anyhow' dynamic structures of people, processes, and technology networks.

\subsection{Managerial Command and Control Challenge of Next Generation KMS}

Organizational controls tend to seek compliance with pre-defined goals that need to be achieved using predetermined 'best practices' and standard operating procedures. Such organizational controls tend to ensure conformity by enforcing task definition, measurement and control, yet they may inhibit creativity and initiative. Enforcement of such controls is essentially a negative activity since it defines "what cannot be done" (Stout 1980) and reinforces a process of single loop learning with its primary emphasis on error avoidance (Argyris 1994). Given the premium on innovation of customer value propositions, business value propositions and business models, organizations in dynamically changing environments need to encourage experimentation. Design of new information architectures thus needs to take into consideration ambiguity, inconsistency, multiple perspectives, and impermanency of existing information. Such architectures need to be designed along the principles of flexible and adaptive information systems that facilitate exploitation of previous experiences while ensuring that memory of the past doesn't hinder ongoing experimentation and adaptation for the discontinuous future.

A key challenge for managers in the forthcoming turbulent environment will be cultivating commitment of knowledge workers to the organizational vision. As it becomes increasingly difficult to specify longterm goals and objectives, such commitment would facilitate real-time strategizing in accord with the organizational vision and its real time implementation on the frontlines. Knowledge workers would need to take autonomous roles of self-leadership and self-regulation as they would be best positioned to sense the dynamic changes in their immediate business environment. Compliance will lose its effectiveness as the managerial tool of control as managers removed from the frontlines would have less and less knowledge about the changing dynamics for efficient decision-making. Managers would need to facilitate the confidence of knowledge workers in acting on incomplete information, trusting their own judgments, and taking decisive actions for capturing increasingly shorter windows of opportunity. In the new world of business, the control over employees will be ultimately self-imposed.

Argyris (1990) has referred to the transition from traditional external control mechanisms to the paradigm of self-control as "the current revolution in management theory." Complementary views have been expressed by other scholars (cf: Bartlett and Ghoshal, 1995; Ghoshal and Bartlett, 1996; Malhotra $2002 \mathrm{~b}$ ) to de-emphasize conformance to the status quo so that such prevailing practices may be continuously assessed from multiple divergent perspectives. The explicit bias of command and control 
systems for seeking compliance makes these systems inadequate for motivating divergence-oriented interpretations that are necessary for ill-structured and complex environments. Systems designed to ensure compliance might ensure obedience to given rules, but they do not facilitate the detection and correction of gaps between the institutionalized inputs, logic, and outcomes, and those necessary for the organization's survival and competence.

\subsection{Economic Returns Challenge of Next Generation KMS}

Some economists (cf: Brian Arthur, 1994) have argued that the production, and distribution of knowledgebased goods and services should create and sustain increasing returns in contrast to diminishing returns that are characteristic of the industrial goods and services. The traditional factors of production are constrained by a threshold of scale and scope as every unit increase in land, labor, or capital results in diminishing returns on every incremental unit beyond that threshold. In contrast, information and knowledge products seem to be governed by a different law of economic returns: investment in every additional unit of information or knowledge created and utilized could result in progressively higher returns. It is important to observe, however, actual realization of such returns requires fundamental rethinking of not only the nature of the product or service, but also its distribution channels as well as the processes underlying its creation, distribution, and, utilization. Increasing digitization and virtualization of business processes without rethinking fundamental premises of the traditional models of products and service definitions has been responsible for the demise of many over-hyped venture-capital funded enterprises.

While 'plug-and-play' technologies could enable rapid adaptability of integrated technology infrastructures, success of the business performance outcomes will be still dependent upon sustained business relationships with collaborators as well as potential competitors. Designers of the next generation KMS would need to understand how enterprise information architectures for intra- and inter-enterprise integration of business processes could enable relationship-building capabilities. This will facilitate sharing of accurate, complete, and timely information by stakeholders across inter-enterprise boundaries to achieve true integration of information flows. Understanding how information sharing occurs in emergent and selfdesigned communities of practice such as those supporting open-source technologies could perhaps facilitate this process.

A related issue is that of the incentives and rewards that are often used for justifying the economic rationale for knowledge sharing by employees as well as outsiders such as customers and suppliers. Knowledge managers responsible for success of KMS and knowledge sharing will need to reconcile contractual measures such as punitive covenants with the need for trust and loyalty of customers, employees, partners, and suppliers. This is particularly true about information-sharing environments that emerge from self-selection of organizations and entities that cooperate with each other based on shared concerns despite the absence of formal controls, rewards or incentives. These issues will gain greater importance with the emergence of Internet based exchanges and global knowledge economies for knowledge, expertise, skills and intellectual capital in which the free market of knowledge is just a few mouse-clicks away (Malhotra, 2002c). Design of incentives for knowledge sharing must consider that institutional controls as well as monetary rewards and incentives are not necessary and do not guarantee the desired knowledge sharing behavior. PricewaterhouseCoopers presents an interesting example of institutionalized formal knowledge harvesting and re-use existing side-by-side with informal ad hoc knowledge exchange and knowledge creation. In this company, the formal and institutionalized KnoweldgeCurve intranet has proven effective as a means for sharing routine and structured information relevant to worldwide employees, while the informal and ad hoc e-mail list, Kraken, has shown tremendous potential for hooking up "self-selected creatives" across various divisions and departments.

\section{Summary and Recommendations For Knowledge Management Executives}

Corporate executives are demanding better justification for investments in KMS infrastructures and expected business performance outcomes. They realize that the next generation KMS must be based on 
ongoing innovation of business value propositions and ext ended inter-enterprise value networks. Many of them want to know how investments in new KMS architectures and "solutions" would contribute to the adaptability of their businesses to unprecedented and rapid pace of change. Accordingly, in establishing the agenda for digitization of their enterprises, knowledge management executives must recognize that their companies can create viable KMS only by attending to the fundamentals of agility and flexibility. The unprecedented level and scope of integration of information flows within and across enterprise boundaries has motivated design of knowledge management architectures based on highly integrated technologies.

Business environments characterized by rapid and radical change put premium on continuous business model innovation to deliver novel, sustainable and competitively viable customer value propositions. Hence, the design of KMS should ensure that adaptation and innovation of business performance outcomes occurs in alignment with changing dynamics of the business environment. This would prevent the failure of KMS caused by the gaps between the value these enterprises create and the value demanded by changing market conditions, consumer preferences, competitive offerings, and, changing business models, and, industry structures. In addition the design of KMS must give due consideration to moderating and intervening behavioral and sociological variables such as attention, motivation, commitment, creativity, and, innovation discussed in Model 2 to ensure that computational inputs [including enabling technologies] and organizational inputs result in effective business performance. This would prevent the failure of KMS caused by the gaps between the data, information technology, best practices, etc., and the business performance outcomes. As explained earlier, conceiving multiple future trajectories of the information technology and human inputs embedded in the KMS can diminish the risk of rapid obsolescence of such systems as they can be readily adapted to innovative business value propositions and customer value propositions. The overriding challenge for the organizations is to effectively address the dialectic of knowledge harvesting and knowledge creation. Enablers and constraints of KMS were enumerated in the form of seven challenges related to business and technology strategy, organizational control, information sharing culture, knowledge representation, organization structure, managerial command and control, and, economic returns.

The architects of next generation KMS cannot afford to treat strategic sustainability of business models, related organizational cultural challenges, and, dependence of these architectures on true integrated information flows as afterthoughts. To successfully manage these challenges, KMS designers must take a holistic approach to designing inter- and intra-organizational "systems" with due consideration not only for the technological design, but also for the design of strategic sustainability of these systems. This approach is expected to provide the needed balance of integration and flexibility required for next generation KMS architectures. Where 'disruptive technologies' alone fell short of expectations, the same technologies could provide the winning recipes for success when coupled with 'disruptive customer value propositions'. Organizational competence and success ultimately depends upon KMS architectures that can enable agile

and adaptive enterprises skilled in creating innovative business models driven by unique, interesting, and competitive customer value propositions.

\section{Acknowledgements}

The content, discussions, and schematic representations in this chapter are based upon author's original works including authored and in-print publications, working papers, keynote presentations, and speeches. 


\section{References}

Applegate, L., Cash, J. and Mills D.Q. (1988). "Information Technology and Tomorrow's Manager. In McGowan, W.G. (Ed.) Revolution in Real Time: Managing Information Technology in the 1990s. Boston, MA: Harvard Business School Press, 33-48.

Argyris, C. (1990). Integrating the Individual and the Organization. New Brunswick, NJ: Transaction.

Argyris, C. (1994). Good Communication that Blocks Learning. Harvard Business Review, JulyAugust, 77-85.

Arthur, B. (1996). Increasing Returns and the New World of Business. Harvard Business Review, 74, $4,100-109$.

Bartlett, C.A. and Ghoshal, S.(1995). Changing the Role of the Top Management: Beyond Systems to People. Harvard Business Review, May-June, 132-142.

Bruner, J.(1990). Acts of Meaning. Cambridge, MA: Harvard University Press.

Business Week (2001). Understanding A New World of Uncertainty And Risk. October 8.

Churchman, C.W. (1971). The Design of Inquiring Systems. New York, NY: Basic Books.

Davidow, W.H. and Malone, M.S. (1992). The Virtual Corporation. New York, NY: HarperCollins.

Drucker, P.F.(1994). The Theory of Business. Harvard Business Review, September-October, 95-104.

Ghoshal, S. \& Bartlett, C.A. (1996). Rebuilding Behavioral Context: A Blueprint for Corporate Renewal. Sloan Management Review, Winter, 23-36.

Kelly, G.A.(1963). A Theory of Personality: The Psychology of Personal Constructs. New York, NY: W.W. Norton \& Co.

Landau, M. and Stout, Jr., R.(1979). To Manage is Not to Control: Or the Folly of Type II Errors. Public Administration Review, March/April, 148-156.

Malhotra, Y. and Kirsch, L.J. (1996). Personal Construct Analysis of Self-Control in IS Adoption: Empirical Evidence from Comparative Case Studies of IS Users \& IS Champions. Proceedings of the First INFORMS Conference on Information Systems and Technology, 105-114.

Malhotra, Y.(1997). Knowledge Management in Inquiring Organizations. Proceedings of the Americas Conference in Information Systems, 293-295.

[Available online at www.kmbook.com ]

Malhotra, Y. (1998). Role of Social Influence, Self Determination and Quality of Use in Information Technology Acceptance and Utilization: A Theoretical Framework and Empirical Field Study. Unpublished Ph.D. thesis, Katz Graduate School of Business, University of Pittsburgh. 
Malhotra, Y. (1999). Bringing the Adopter Back Into the Adoption Process: A Personal Construction Framework of Information Technology Adoption. Journal of High Technology Management Research, 10, 1, 79-104.

Malhotra, Y. and Galletta, D.F.(1999). Extending the Technology Acceptance Model to Account for Social Influence: Theoretical Bases and Empirical Validation. Proceedings of the Hawaii International Conference on System Sciences, 6-19.

Malhotra, Y.(2000a). From Information Management to Knowledge Management: Beyond the 'HiTech Hidebound' Systems. In Srikantaiah, K. \& Koenig, M.E.D. (Eds.), Knowledge Management for the Information Professional. Medford, N.J.: Information Today Inc., 37-61.

[Available online at www.kmbook.com ]

Malhotra, Y.(2000b). Knowledge Management and New Organization Forms: A Framework for Business Model Innovation. Information Resources Management Journal, 13, 1, 5-14.

[Available online at www.kmbook.com ]

Malhotra, Y. (Ed.) (2000c), Knowledge Management and Virtual Organizations. Hershey: PA, Idea Group Publishing.

Malhotra, Y.(2000d). Knowledge Management for E-Business Performance: Advancing Information Strategy to 'Internet Time'. Information Strategy: The Executive's Journal, 16,4, 5-16.

[Available online at www.kmbook.com ]

Malhotra, Y.(2001). Expert Systems for Knowledge Management: Crossing the Chasm Between Information Processing and Sense Making. Expert Systems With Applications, 20,1, 7-16.

Malhotra, Y. (Ed.) (2001b). Knowledge Management and Business Model Innovation. Hershey: PA, Idea Group Publishing.

Malhotra, Y. (Ed.) (2002a). Enabling Knowledge Exchanges for E-Business Communities. Information Strategy: The Executive's Journal, 18(3), 26-31, Spring.

Malhotra, Y. (2002b). Is Knowledge Management Really an Oxymoron? Unraveling the Role of Organizational Controls in Knowledge Management. In White, D. (Ed.), Knowledge Mapping and Management. Hershey, PA Idea Group Publishing, 1-13.

Malhotra, Y. (2002c). Knowledge Assets in the Global Economy: Assessment of National Intellectual Capital. In F. Tan (Ed.), Advanced Topics in Global Information Management. Hershey, PA: Idea Group Publishing, 329-345.

Malhotra, Y.(in press). Information Ecology and Knowledge Management: Toward Knowledge Ecology for Hyperturbulent Organizational Environments. In Kiel, D.L. (Ed.), UNESCO Encyclopedia of Life Support Systems (EOLSS). Paris, France: EOLSS Publishers.

Mason, R.O. \& Mitroff, I.I.(1973). A Program for Research on Management Information Systems. Management Science, 19, 5, 475-487. 
Mathur, S.S. and Kenyon, A.(1997). Our Strategy is What We Sell. Long Range Planning, 30, June.

Morris, C.W.(1938). Foundations of the Theory of Signs. Chicago, IL: University of Chicago Press.

Nadler, D.A. \& Shaw, R.B. (1995). Change Leadership: Core Competency for the Twenty-First Century, in Nadler, D.A., Shaw, R.B. and Walton, A.E. Discontinuous Change: Leading Organizational Transformation. San Franscisco, CA: Jossey-Bass.

Nonaka, I. and Takeuchi, H. (1995). The Knowledge-Creating Company, New York, NY: Oxford University Press.

Prusak, L. (2001). Where Did Knowledge Management Come From?. IBM Systems Journal, 4, 10021007.

Oracle Magazine. (1998). Knowledge Management in the Information Age. May, $\mathrm{URL}=\mathrm{http}: / / \mathrm{www} \cdot$ oracle.com/oramag/oracle/98-May/cov1.html

[last verified at the time of submission of the article.]

Stout, R., Jr. (1980). Management or Control?: The Organizational Challenge. Bloomington, IN: Indiana University Press.

Strombach, W.(1986). Information in Epistemological and Ontological Perspective. In C. Mitcham, C. and Huning, A. (Eds.), Philosophy and Technology II: Information Technology and Computers in Theory and Practice. D. Dordrecht, Holland: Reidel Publishing Co.

Wenger, E., McDermott, R., Snyder, W.M. (2002). Cultivating Communities of Practice: A Guide to Managing Knowledge. MA: Harvard Business School. 


\section{Index Terms}

Design of Knowledge Management Systems

Successful Knowledge Management Systems

Enablers and Constraints of Knowledge Management

Adaptive Systems for Radical Discontinuous Change

Knowledge Harvesting and Knowledge Reuse

Knowledge Creation

Information Processing and Sense Making

Strategic, Social, and, Behavioral Aspects of Knowledge Management

Transformation of Knowledge Work

Transformation of Knowledge Organizations

Business Value Propositions

Customer Value Propositions

Knowledge Management Failure

Business Model Innovation

New Business Models 


\section{Profiles}

Yogesh Malhotra (yogesh.malhotra@brint.com)

Dr. Yogesh Malhotra is the Founding Chairman and CKO of the BRINT Institute, the New York based globally branded elearning, research, and advisory firm. He taught on the faculty of Executive MBA programs at the Kellogg School of Management at Northwestern University and the Graduate School of Industrial Administration at the Carnegie Mellon University and currently holds a professorial appointment at the Syracuse University. An ISWorld survey conducted by a Drexel University professor ranked Dr. Malhotra in the two most influential worldwide practitioners and researchers in the field of Information Systems and Knowledge Management. He is the author or editor of two books, four research journal special issues, and several refereed and invited articles on Knowledge Management, eBusiness, and Information Systems. He serves on the Board of Directors of Knowledge Management Consortium International and is a Founding Member of the Ziff Davis Standard for Internet Commerce. His interviews and analyses and reviews of his award-winning elearning and knowledge management ventures have appeared in Business Week, Wall Street Journal, Fortune, Fast Company, Business 2.0, CIO Magazine, Computerworld, Information Week, KM World and hundreds of other TV, print and media channels around the world. As an internationally sought speaker and advisor, his keynote speeches and advisory engagements address the concerns of seniormost corporate and technology executives from some of the largest corporations and consulting groups between Silicon Valley and Seoul as well as technology and policy heads of some of the world's most prominent governments. His research has been having worldwide influence on the design of next generation e-learning and knowledge management policies, strategies, and, technology infrastructures as well as definition of high-performance adaptive business models; national and institutional education and learning frameworks; and, information and technology policies of major corporations, worldwide governments, and national knowledge economies. He is profiled in the Marquis Who's Who in the World, Millennium Edition, and, Marquis Who's Who in Finance and Industry.

http://www.yogeshmalhotra.com/ 